\title{
Tecnologia de processos como estratégia de operações: avaliação e vantagens operacionais
}

\author{
RESUMO
}

\section{Wandick Leão}

wandicklf@insper.edu.br

Ensino e Pesquisa São Paulo - SP - Brasil
Nas últimas décadas, uma alternativa que tem sido utilizada para auxílio da gestão e da estratégia de operações é a implantação de tecnologias de processos, isto é, máquinas, dispositivos e equipamentos que auxiliam na produção de bens e serviços. Todavia, ainda existem empresas e setores que não aderiram a essa estratégia, talvez, pela mesma necessitar de análises complexas ou ainda de demasiado investimento financeiro. Diante desse quadro, o presente artigo pretende entender como se dá o processo de análise para a implantação da tecnologia de processos e quais os principais benefícios decorrentes dela, especialmente quando analisada como uma estratégia de operações. Para tanto, foi aplicado um estudo de caso em uma montadora do setor automobilístico, onde os resultados e conclusões demonstram que a implantação da tecnologia de processos demanda uma complexa análise com critérios e dimensões específicas, mas que por outro lado, gera benefícios robustos, especialmente em relação à capacidade de produção e à qualidade do que é produzido.

PALAVRAS-CHAVE: Tecnologia de Processos. Estratégia de Operações. Estudo de caso. Qualidade. Capacidade de Produção. 


\section{INTRODUÇÃO}

As organizações existem por uma série de motivos, dentre os quais, se destaca o atendimento das necessidades e satisfação dos consumidores, através de produtos e serviços. A gestão de operações contribui para a união dessas "pontas", isto é, cliente e empresa, pois são as operações que vão criar os respectivos produtos e serviços (HILL, 2000; SCHROEDER, 2008). Desde que a administração se tornou um campo de estudo, gestores, pesquisadores e gurus têm se preocupado na descoberta e concepção de novas formas de se produzir mais e com maior eficiência. Acrescente-se a isso, a ocasião de grandes mudanças no cenário competitivo mundial nas últimas décadas, as quais serviram de combustível para o ensino e a pesquisa em gestão de operações (ARKKADER, 2003). Dentre as várias descobertas realizadas, a aplicação de tecnologias em manufatura é uma prática que tem se desenvolvido através dos séculos e que tem trazido grandes avanços nesse sentido (HILL, 2000). Afinal, ela tem a capacidade de promover vários benefícios à transformação de materiais, que antes era realizada de modo artesanal, como por exemplo, maior qualidade, rapidez e confiabilidade (SLACK; LEWIS, 2009). Por outro lado, a inserção de uma nova tecnologia pode também reduzir custos, melhorar os processos de produção e agregar maior valor aos produtos produzidos (PAIVA; FINGER, TEIXEIRA, 2014). Ainda, segundo Hayes et al. (2008), pequenas alterações em relação aos processos de produção, podem acarretar impactos significativos junto à qualidade e o caráter do produto. Em resumo, a criação de operações diferenciadas pode trazer impacto estratégico e sustentável para a organização (BARNEY, 1991; SCHROEDER, 2008; TEECE; SHUEN; PISANO, 1997).

No entanto, apesar das evidencias que corroboram esses benefícios, algumas empresas e setores ainda não implantaram tecnologias em suas operações, talvez por ser algo complexo de se realizar e que necessite de análise detalhada em relação ao impacto estratégico que esse procedimento pode causar nas operações. Diante desse quadro, o presente artigo busca entender com maior profundidade essas questões sobre "como se dá o processo de avaliação para implantação de uma tecnologia de processos e quais os benefícios que ela pode trazer para as empresas sob o ponto de vista da estratégia de operações ?". Para a compreensão dessas proposições foi realizado um estudo de caso, tendo como fontes de dados, a entrevista, documentos e a observação direta de uma linha de montagem (produção) em uma empresa multinacional do segmento automobilístico.

\section{REVISÃO DA LITERATURA}

As próximas seções trazem a revisão da literatura, retratando a gestão de operações e o seu papel no processo de transformação e depois mostrando como a tecnologia de processos pode influenciar essas atividades. Nessa revisão, são exemplificadas também algumas tecnologias comumente utilizadas em organizações de manufatura e por último são discutidos os critérios e as dimensões de análise para a avaliação e implantação da tecnologia de processo. 


\section{Processo de transformação, gestão e estratégia de operações}

A gestão de operações trata de todas as atividades relacionadas à entrega de produtos e serviços, desde a compra dos materiais passando pelo processo de transformação até à etapa de distribuição (HAYES et al., 2008). Essas etapas podem ser ilustradas como um processo de transformação, onde as entradas (inputs), são os diversos recursos materiais necessários para a produção, passando posteriormente pelo processo de transformação que finalmente entrega saídas (outputs), que são os produtos e serviços, demandados pelos clientes. O processo de transformação pode ter uma estrutura simples, como por exemplo, os encontrados em pequenas organizações como padarias, oficinas mecânicas e consultórios médicos, mas, também podem ser extremamente complexos, como os encontrados em redes de fast food, varejistas e montadoras. A Jaipur Rugs, por exemplo, é uma fabricante de tapetes indianos à mão, que possui um sistema complexo de produção que começa com a aquisição global de matérias primas e termina com a distribuição global de produtos acabados (PRAHALAD, 2005).

Exemplos como o da Jaipur Rugs, mostram na prática que o processo de transformação e a gestão de operações podem se tornar atividades substancialmente estratégicas, dada a amplitude e contexto de mercado que uma empresa pode alcançar, desta forma, as operações acabam necessitando de um olhar mais estratégico (ver Figura 1). É nesse momento que a organização necessita de uma estratégia de operações, onde questões como ambiente competitivo, desenvolvimento a longo prazo, processos e recursos de produção devem ser analisados e geridos a fim de se alcançar vantagens sustentáveis e competitivas (SCHROEDER, 2008; SLACK; LEWIS, 2009). Portanto, a estratégia de operações tem o papel de definir todas as decisões e atividades relacionadas com as operações de produção, que visam trazer vantagens e melhores formas de se alcançar os objetivos gerais da organização (HAYES et al., 2008; SLACK et al., 2012). Nesse trabalho, será avaliada, uma dessas melhores formas, através da implantação e uso das tecnologias de processos nas atividades de produção. 
Figura 1 - A conexão entre processo de transformação, gestão e estratégia de operações

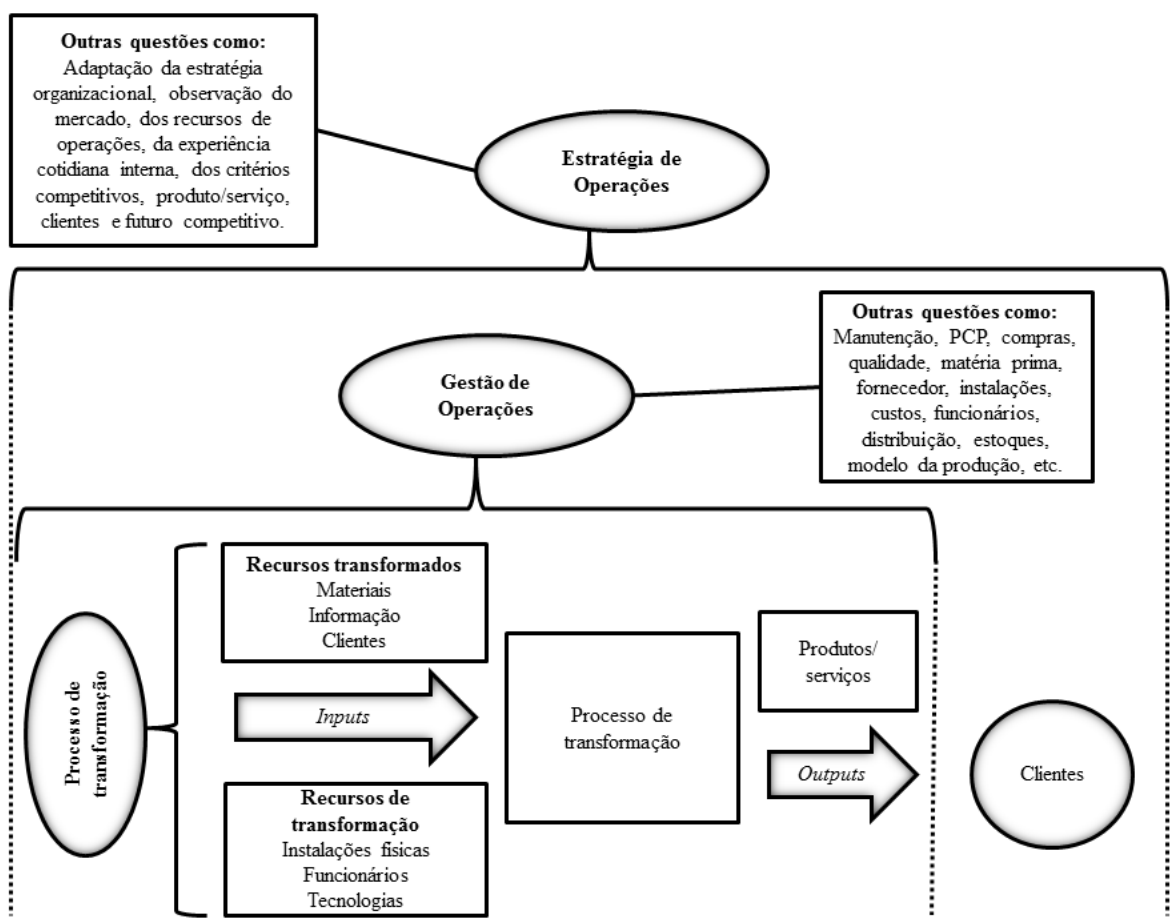

Fonte: Elaborado pelo autor com base em Meredith e Shafer (2002), Schroeder (2008), Slack, Brandon-Jones e Johnston (2015) e Slack e Lewis (2009)

\section{Tecnologia de processos}

De acordo com Tigre (2006), o termo tecnologia pode ser definido como o conhecimento sobre técnicas, isto é, o conhecimento de como se fazer ou produzir algo. Mais especificamente, em relação ao contexto fabril, as tecnologias de processos são as tecnologias aplicadas aos processos de produção de uma empresa (MAIER; SCHROEDER, 2001), isto é, trata-se do conjunto de máquinas, equipamentos e dispositivos que auxiliam nas operações de produção e entrega de produtos e/ou serviços (SLACK; BRANDON-JONES; JOHNSTON, 2015). Gonçalves (2000), afirma que a tecnologia tem importante função dentro dos processos organizacionais, produzindo relevante influencia tanto na forma de se realizar o trabalho, como em sua gestão, isto é, seja ela simples ou sofisticada, ela acaba fazendo parte de toda a estrutura da empresa (JOHNSTON; CLARK, 2012). Cabe destacar, que usualmente, as tecnologias são empregadas para se otimizar os processos produtivos e organizacionais, que são os responsáveis por transformar insumos em resultados (MAXIMIANO, 2010) ou ainda para a sustentação da estratégia de operações (CHASE; AQUILANO; JACOBS, 2006). Por isso, Damião e Severino (2010), colocam que a observação dos processos organizacionais é sempre bem vinda, haja vista que os mesmos possuem papel significativo no desempenho das empresas. 
Como mencionado no início do artigo, este estudo analisa uma empresa do setor de transformação industrial, no caso, uma montadora de automóveis, portanto, trata-se de uma empresa que transforma recursos materiais em bens tangíveis. Sendo assim, com base em alguns livros-texto sobre gestão de operações (por exemplo, GAITHER; FRAZIER, 2005; MARTINS; LAUGENI, 1998; SLACK et al., 2012), serão ilustradas algumas tecnologias de processos comumente utilizadas nesse segmento, cabe ressaltar que as tecnologias a seguir exemplificadas atuam de modo direto no processo de produção de mercadorias e serviços (SLACK; LEWIS, 2009). Através dessa revisão literária, percebe-se a influência desses tipos de tecnologias nos processos de produção, evidenciando suas vantagens em várias esferas.

Máquinas ferramentas de controle numérico (CNC): Uma das primeiras e mais antigas tecnologias produzidas para auxilio no setor industrial, as máquinas ferramentas são equipamentos acoplados a um computador que controla e executa atividades de corte, perfuração, aperto e outras de acordo com a sua respectiva função no processo de produção, por exemplo, torno, fresadora, oxicorte, furadeira, jato de água. Em virtude de seu acoplamento a um computador, essas máquinas podem ser reprogramadas de acordo com a demanda da produção. Essas máquinas podem trazer diversos benefícios para a produção, como por exemplo, qualidade, precisão e repetitividade do processo, produtividade através da eliminação de erros de operador, além da possibilidade de se estocar ferramentas de corte dentro do próprio equipamento.

Robôs: Segundo Gaither e Frazier (2005), o primeiro robô da era industrial surgiu nos anos de 1950, por coincidência em uma fábrica da General Motors. Bastante utilizado na indústria de transformação, geralmente realizam atividades comuns, como soldagem, pintura, empilhamento, esmerilhamento, embalagem, carregamento e descarregamento de máquinas. No entanto, também podem ser empregados em atividades mais complexas, como aconteceu na operação de limpeza dos escombros das torres gêmeas em Nova lorque (SLACK; BRANDONJONES; JOHNSTON, 2015). Os robôs permitem ao processo de produção, agilidade e várias formas de se produzir algo (DE MASI, 2000). Além disso, podem operar em ambiente hostil ao ser humano (por exemplo, calor, ruído, poeira e escuridão não são problemas para eles), ademais seus resultados em termos de produtos e serviços podem ter mais qualidade, uniformidade e flexibilidade, pois são previsíveis e operam repetidamente, sem fadiga (GAITHER; FRAZIER).

Veículos guiados automaticamente (AGV): Os veículos guiados automaticamente são um ou mais "carrinhos" que se move $(\mathrm{m})$ sozinho(s), isto é, através de instruções computadorizadas, por estações de trabalho e linhas de produção, carregando e entregando nos locais e horários programados, diversos materiais e recursos necessários ao processo de produção (MARTINS; LAUGENI, 1998). De acordo com Pérez (2010), foi Leonardo Da Vinci, uma das pessoas que se dedicou amplamente ao estudo da robótica bem como de mecanismos que reproduziam movimentos e características nas quais ele estava interessado em sua 
época. Algumas dessas invenções eram verdadeiros autômatos complexos, que lembram com muita familiaridade os atuais veículos guiados automaticamente.

Sistemas flexíveis de manufatura (FMS): Quando se reúne todos em uma mesma fábrica, robôs, veículos automaticamente guiados, máquinas ferramentas e outros dispositivos e equipamentos tecnológicos é formado um sistema flexível de manufatura (FMS), que justamente por ser um sistema tem o papel de conectar todos os componentes tecnológicos da produção (HILL, 2000). Os sistemas flexíveis de manufatura são grupos de máquinas, equipamentos e outras instalações automatizadas que auxiliam em todo o sistema de produção, seja nas estações de trabalho, carga e descarga e manuseio de materiais, ambos integrados por um sistema de computador (GAITHER; FRAZIER, 2005; SLACK et al., 2012). Cabe destacar, que essa flexibilidade no sistema é uma de suas principais vantagens, dado que as operações podem ser modificadas e personalizadas segundo a necessidade da empresa e de seus clientes, ou seja, é uma tecnologia que se destaca e traz vantagens à produção, justamente pelo seu caráter flexível.

Manufatura Integrada por computador (CIM): Por outro lado, quando um FMS, isto é, um sistema flexível de manufatura, além de integrar máquinas responsáveis pela produção direta, como robôs, AGV's, CNC's e outros, passa a englobar também, tecnologias de projeto e design, programação e outros softwares, ele passa a ser uma manufatura integrada por computador. Segundo Gaither e Frazier (2005), a principal característica do CIM é que ele conecta e integra vários sistemas que dão sustentação à manufatura. Em meados de 1990, Machline (1994) já previa o alastramento dessa tecnologia pelas indústrias de manufatura, uma vez que o critério qualidade também se disseminava pela produção de vários outros tipos de produtos e que por sua vez, acabava sendo um dos principais outputs alcançado pelo uso desse sistema.

\section{Avaliação da tecnologia de processo}

O uso apropriado de tecnologia é sempre uma característica crítica a ser considerada no desenvolvimento dos processos de produção (HILL, 2000). Por isso, toda vez que uma organização se dispõe à aquisição de algo, ela estuda e avalia sistematicamente todos os aspectos e impactos possíveis dessa compra. No caso das tecnologias de processo, essa preocupação é ainda maior, dado o alto investimento que elas requerem. Apesar de não existir uma lista de atributos que possa avaliar todas as situações possíveis, mostra-se útil a consideração de pelo menos seis critérios ou dimensões relacionadas à aquisição de uma tecnologia de processo (SLACK; LEWIS, 2009). Os três primeiros critérios têm maior relação com a gestão de operações como um todo, já os quatro últimos são relacionados em como vai se desenvolver a operação de produção (ver Figura 2), cabe destacar que todos os itens a seguir são discutidos e ampliados de acordo com Slack (2002) e Slack e Lewis (2009).

Viabilidade: A viabilidade se refere a real possibilidade de se adquirir a nova tecnologia, onde é preciso analisar a questão financeira da compra, isto é, existe a 
quantia de dinheiro necessária? Quanto tempo será necessário para o investimento ser pago? Se não existe o dinheiro, vale a pena a busca por empréstimos? O retorno futuro cobre os juros do empréstimo? De igual modo é preciso avaliar também os recursos administrativos existentes, como por exemplo, os funcionários atuais têm conhecimento para operar a tecnologia? Será preciso capacitá-los através de cursos? Isso geraria mais custos financeiros? Quanto tempo será necessário para que essa tecnologia seja implantada e comece a funcionar normalmente?

Aceitabilidade: No caso da aceitabilidade, busca-se ter ciência sobre todos os potencias efeitos positivos que a empresa almeja, como por exemplo, vai haver mais lucro? A produção será mais rápida? Vão diminuir as falhas e os erros de produção? O produto terá um acabamento mais padronizado? Essas mudanças terão efeitos positivos tanto nos objetivos estratégicos como nos operacionais? Ou só em um deles?

Vulnerabilidade: $O$ último critério a ser analisado em termos de gestão, trata da vulnerabilidade ou o quanto a empresa está exposta, caso algo venha a dar errado em decorrência da aquisição dessa tecnologia.

Escalabilidade: Nesse critério a organização precisa analisar o seu produto/serviço em termos de resultado. Primeiramente em relação à escalabilidade, a quantidade de produtos a ser fabricada pode vir a variar de modo relevante?, neste caso, a tecnologia a ser adotada dispõe de flexibilidade, podendo ser reprogramada para a produção de quantidades diferentes? Esse critério afeta substancialmente tanto os custos de aquisição como de operacionalização (HAYES et al., 2008).

Variedade: Nessa mesma vertente, observando-se o critério variedade, o produto a ser fabricado tem várias opções ou modelos que necessitam de operações distintas na sua fabricação? Isto é, caso o produto tenha várias opções distintas entre si, a tecnologia de processos pode ser reprogramada para atender essas diferenças no momento da produção?

Automação: O grau de automação diz respeito ao percentual de interferência humana na tecnologia de processo. Afinal, toda tecnologia até certo ponto precisa da intervenção humana (SLACK; BRANDON-JONES; JOHNSTON, 2015). Dessa forma, é necessário saber o quanto de intervenção humana ou autonomia tecnológica a empresa prefere no momento em que a tecnologia de processos estiver em uso.

Conectividade: Como último critério, é preciso analisar também a conectividade ou o grau de conexão que a tecnologia a ser adquirida tem em relação aos outros dispositivos tecnológicos que possam já existir na empresa, bem 
como naqueles que podem vir a ser adquiridos depois, para serem acoplados à tecnologia que está sendo adquirida neste momento.

Figura 2 - Avaliação da tecnologia de processo

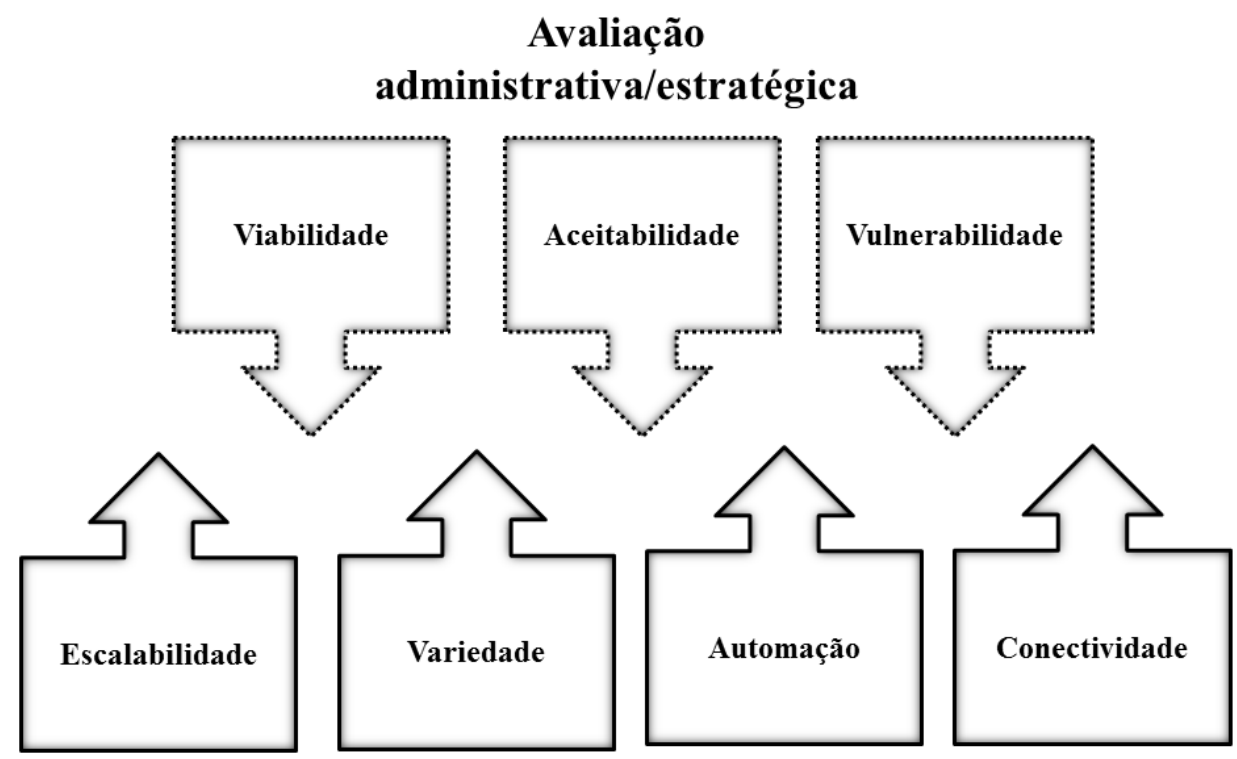

Avaliação operacional

Fonte: Elaborado pelo autor com base em Slack e Lewis (2009) e Slack (2002)

\section{METODOLOGIA E COLETA DE DADOS}

O presente estudo busca compreender "como se dá o processo de avaliação para implantação de uma tecnologia e quais os benefícios que ela pode trazer para as empresas que as possuem", sendo assim, foi escolhido o estudo de caso como método para a coleta dos dados. O estudo de caso concede a oportunidade do exame aprofundado de um objeto de pesquisa (ROESCH, 1999; ROTH, 2007), permitindo a compreensão do "que" e "como" acontecem determinados fenômenos dentro de seus respectivos contextos (YIN, 2010). O cruzamento das informações coletadas através de diversas fontes de dados permite o entendimento e o aprofundamento de teorias já existentes (McCUTCHEON; MEREDITH, 1993; VOSS; TSIKRIKTSIS; FROHLICH, 2002). De acordo com Arkkader (2003), as pesquisas em operações no Brasil precisam evoluir, dentre as várias sugestões da autora, é necessário um adequado planejamento e a realização de pesquisas de campo, sendo assim, em relação ao método aplicado e seus procedimentos, essa pesquisa seguiu as recomendações de Yin (2010), como pode ser notado na Figura 3: 
Figura 3 - Método do estudo de caso

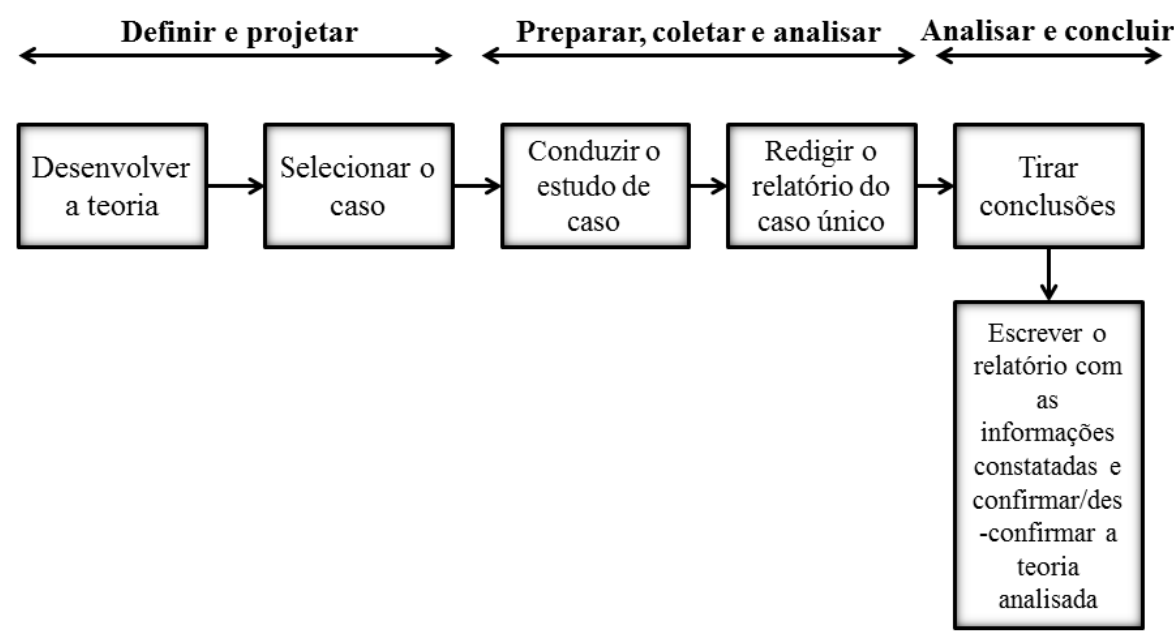

Fonte: Yin (2010)

Ainda segundo Yin (2010), existem vários projetos para estudo de caso, neste trabalho optou-se pelo estudo de caso único, por se tratar de um caso típico ou representativo em relação ao setor analisado, no caso o setor automobilístico, tendo como unidade de análise, uma organização, onde as informações coletadas têm o papel de corroborar as proposições desse trabalho bem como demonstrar de modo empírico as afirmações teóricas. Além disso, em termos de resultado final, esse trabalho busca trazer explicações para as questões propostas bem como uma análise descritiva sem interferir no estudo realizado (STAKE, 1994). De acordo com Creswell (2010) e Yin (2010), no que diz respeito aos procedimentos operacionais ou fontes de evidência, esse trabalhou optou pela entrevista, a observação direta e a análise de documentos (ver Tabela 1).

Tabela 1 - Fonte dos dados

\begin{tabular}{|c|c|c|c|}
\hline Caso & $\begin{array}{l}\text { Fonte dos } \\
\text { dados }\end{array}$ & Detalhes especificos das fontes & Quantidade \\
\hline \multirow{4}{*}{ GM } & Entrevista & Engenheiro de produção (responsável direto) & 1 \\
\hline & Visita in loco & $\begin{array}{l}\text { Visita no interior da planta como observador, } \\
\text { acompanhado por profissional da empresa que } \\
\text { explicou todo o processo de produção do início ao } \\
\text { fim }\end{array}$ & 1 \\
\hline & Documentos & $\begin{array}{l}\text { Revistas e publicações de circulação interna da } \\
\text { empresa }\end{array}$ & 5 \\
\hline & $\begin{array}{l}\text { Informações } \\
\text { em sites }\end{array}$ & $\begin{array}{l}\text { Informações e notícias sobre as adaptações da } \\
\text { planta para a produção do novo veículo }\end{array}$ & 5 \\
\hline
\end{tabular}

Fonte: Elaborado pelo autor (2017).

Nas próximas subseções, são trazidas algumas informações sobre a empresa, tanto em contexto mundial como sobre a matriz brasileira, a planta industrial onde foi realizado o estudo e a nova linha de produção, montada especialmente para a última reestilização de um dos modelos da marca. 


\section{General Motors}

A General Motors (GM) é uma empresa multinacional americana fundada em 1908 com sua sede global em Detroit. Cabe mencionar que a mesma já foi objeto de vários estudos acadêmicos, não só internacionais como nacionais (CONSONI; BERNARDES; SCUR, 2017; GUARDABASSIO et al., 2014; LUZ, 2009; AMATUCCl; BERNARDES, 2007). Sua principal área de negócios sempre foi a fabricação de automóveis, não à toa, com o passar do tempo adquiriu várias outras marcas ao grupo, além de prestar suporte tecnológico avançado para outras montadoras. Atuando com vários parceiros estratégicos, a GM está presente e produzindo veículos em trinta países, no entanto, dada a amplitude do mercado em que atua, a empresa garante mais de 200 mil postos de trabalho em 120 países ao redor do mundo, sendo seu principal slogan a excelência em qualidade e inovação.

A GM chegou ao Brasil através da marca Chevrolet em 1925, dois anos depois começou a construção da fábrica em São Caetano do Sul e no ano seguinte iniciou a produção de veículos, todavia, a fábrica só foi inaugurada em 1930. O complexo de São José dos Campos teve sua construção iniciada em 1957 e sua inauguração em 1959, pelo então Presidente Juscelino Kubitschek. O primeiro modelo de passeio da marca no Brasil foi o Opala de 1968, cinco anos depois foi lançado um dos maiores sucessos de vendas da marca no país, o Chevette e em 1982, o Monza. Em 1995, as duas fábricas (São Caetano do Sul e São José dos Campos) conquistaram o certificado de qualidade ISO 9002. Já em 1997, a empresa começou a instalação de sua terceira fábrica no Brasil, em Gravataí (RS), nesse mesmo ano conquistou outra certificação, a ISO 9001 para todas as unidades brasileiras. Em 2011, chegou à sua quarta fábrica, em Joinville (SC) (GENERAL MOTORS DO BRASIL LTDA, 2012) e em 2015 completou 90 anos de atividades no Brasil.

\section{Planta Industrial de São José dos Campos (SJC)}

Pensando estrategicamente na progressão econômica que o Brasil vinha tendo durantes os anos de 1960, a GM escolheu um terreno de $1.634 .008 \mathrm{~m}^{2}$, localizado em São José dos Campos (SJC) para a construção de sua segunda fábrica no país. A fábrica ficaria localizada às margens da Rodovia Presidente Dutra, via que liga as principais capitais do país, como São Paulo, Rio de Janeiro e Minas Gerais, todavia, o elemento essencial que concretizou a escolha do local, foi a proximidade que a planta teria junto à estrada de ferro da Central do Brasil, essa oportunidade permitia a locomoção de materiais e pessoas entre a nova fábrica e a sede localizada no $A B C$ paulista. Os primeiros trabalhadores vieram de São Paulo, Minas Gerais bem como do exterior, essa invasão permitiu ao município um maior desenvolvimento industrial, tecnológico e cultural (GENERAL MOTORS DO BRASIL LTDA, 2012; PANORAMA, 2013).

Atualmente, o complexo é um dos maiores do Brasil, em 2013 já havia produzido mais de 5,5 milhões de veículos e concedia empregos a mais de 7.000 pessoas. Sua área territorial de 2,7 milhões de $\mathrm{m}^{2}$ tem cerca de $500.000 \mathrm{~m}^{2}$ de área construída. A unidade em 2013, abrigava oito fábricas, uma de automóveis (Chevrolet Classic), uma de comerciais leves (Picape S10 e a Trailblazer), duas fábricas de motores (Família I e Família II), uma de transmissões, uma de estamparia, uma linha de injeção e pintura de peças e a última dedicada ao 
Completely Knocked Down (CKD). Em virtude da chegada da produção da Picape S10 e do utilitário esportivo Trailblazer, foram incorporados novos processos de produção. A funilaria e a pintura receberam novos robôs e equipamentos de última geração e, na montagem final, aparelhos sofisticados e de alta tecnologia também foram agregados (PANORAMA, 2013).

\section{RESULTADOS E DISCUSSÃO}

Inicialmente destaca-se a quantidade de tecnologias disseminadas e empregadas na linha de produção da picape, são vários equipamentos, dispositivos e máquinas espalhados pela planta industrial, todos esses instrumentos são essenciais para o aumento da produtividade bem como da garantia de qualidade do produto (PAIVA; FINGER, TEIXEIRA, 2014; SLACK; LEWIS, 2009), corroborando as informações encontradas em Panorama (2013). De todos os exemplos de tecnologias de processamento de materiais mencionados na revisão da literatura, talvez a única que não parece estar disponível na planta de SJC é o AGV, no mais, a planta como um todo parece ser um CIM. A título de exemplo, um dos muitos aparatos tecnológicos da empresa, talvez, o mais simples, seja a apertadeira eletrônica, com controle de torque com variação mínima e sistema error proofing, isto é, a prova de erros, que interrompe o processo de montagem caso algum aperto não seja realizado de modo adequado no interior da estação de trabalho.

Ainda em relação ao extenso uso de tecnologias de processos, quando observada as questões relativas à dimensão ou critério, as mesmas são vistas como prioridades, especialmente no que diz respeito à qualidade e a padronização da produção. No entanto, o conceito ainda se estende para o tratamento da segurança humana, dado que a padronização permite o mapeamento de aspectos críticos relacionados ao desenvolvimento das atividades de produção. $\mathrm{O}$ fator variedade também é considerado como aliado, pois facilita posteriores alterações, permitindo a flexibilização sem perca da qualidade e da padronização. Em relação ao grau de conexão das tecnologias existentes na planta industrial e responsáveis pelos processos de produção, 90\% dos mesmos também são conectados. Interessante que a empresa demonstrou ter relevante preocupação também com os critérios de viabilidade e aceitabilidade, onde destacam-se aspectos como as habilidades humanas para a utilização das tecnologias, necessidade de outros recursos de operação que possam se conectar com a tecnologia a ser adquirida e por último a questão financeira, relativa ao aporte investido nos equipamentos. Nas palavras da empresa, esses aspectos "são importantes e andam lado a lado". Em geral, de acordo com a organização, nessas situações o propósito da aquisição de novas tecnologias de processos, tem relação direta com maiores lucros e melhor desempenho dos recursos empregados no processo de produção, para tanto, em uma tomada de decisão dessa envergadura, um estudo minucioso é elaborada a fim de definir a viabilidade do projeto como um todo.

Diante desses achados, onde a aplicação de tecnologias se mostra essencial e com demasiada presença nos processos de produção analisados, é natural o entendimento de que a intervenção humana é mínima e residual, todavia, a pesquisa trouxe resultados distintos, comprovando que a presença humana ainda é importante e bem presente nos processos de produção, aliás, existem vários funcionários espalhados pela planta, desde operadores a engenheiros, cada qual 
com responsabilidades específicas. Segundo a empresa "mesmo com muita tecnologia, a intervenção humana, ainda é grande, girando em torno de 90\%".

Apesar da existência de outras plantas industriais ao redor do Brasil, as tecnologias empregadas nas linhas de produção, independente do veículo produzido, são as mesmas, cabe destacar, que as práticas e a filosofia de gestão da produção analisadas no momento desse estudo se mostraram bem próximas do modelo moderno de produção ou just in time. A questão da qualidade parece ser um dos principais objetivos da empresa, além das tecnologias empregadas, existem departamentos específicos que acompanham a garantia da qualidade do produto final, isto é, do veículo bem como das peças de reposição que são disponibilizadas no mercado, existe ainda um intenso trabalho de pós venda, responsável pela mensuração de diversos aspectos, especialmente a satisfação dos clientes, portanto não é a toa, o fato da empresa possuir praticamente todas as certificações de qualidade inerentes à processos de produção. Em última instância, o estudo proposto percebe no caso da empresa analisada, que a tecnologia de processos enquanto uma estratégia de operações busca "capacidade de produção e qualidade no que é produzido".

\section{CONSIDERAÇÕES FINAIS}

O propósito desse trabalho era demonstrar como se dá o processo de avaliação para implantação de uma tecnologia de processos e quais os benefícios que ela pode trazer para as empresas sob o ponto de vista da estratégia de operações, servindo de reflexão para organizações que pretendem buscar melhoria e que veem na tecnologia de processos essa oportunidade. 0 estudo de caso realizado trouxe evidencias de que a tecnologia de processos traz implicações preliminares e complexas no sentido da sua avaliação tanto do ponto de vista gerencial, mercadológico e operacional.

Refletindo especificamente sobre os critérios de avaliação para a aquisição da tecnologia de processos, percebe-se que as colocações propostas por Slack (2002) e Slack e Lewis (2009), estão em linha com o que acontece na prática pelas organizações que realizam esse tipo de avaliação. Naturalmente que existe maior complexidade em relação a esta análise, no entanto, os critérios genéricos estruturados pelos dois autores auxiliam no planejamento inicial de outras empresas que querem realizar esse tipo de implantação.

Por outro lado, os benefícios são relevantes, especialmente em relação à capacidade de produção e a qualidade do que é produzido, onde o cliente que é o principal alvo tem a sua disposição produtos de altíssima qualidade e que the passam a devida confiabilidade. Todavia, outra descoberta interessante é o fato de que, apesar dos equipamentos e máquinas tecnológicas terem várias competências melhores quando comparadas ao ser humano, ainda é necessária a intervenção desse último, para que tudo corra bem e sem transtornos.

\section{LIMITAÇÕES E SUGESTÕES PARA FUTUROS ESTUDOS}

A primeira limitação que desponta nessa pesquisa é o estudo de caso único, apesar de se mostrar mais adequada essa abordagem para a presente pesquisa, a mesma não permite a triangulação, comparação e eventual generalização dos 
resultados. Ainda em relação ao método, poderiam ter sido realizadas mais entrevistas com outros funcionários, fornecedores e demais elos da unidade de análise. Já a segunda limitação, diz respeito aos resultados ou benefícios abordados em relação à implantação da tecnologia de processos, como pode se observar, os mesmos são qualitativos e mais ligados ao fator qualidade. Uma terceira questão seria o fato da análise ter sido realizada em uma organização já antiga e bem assentada em seu segmento. Portanto, sugere-se para estudos futuros, a análise de mais de um caso bem como a realização de um número maior de entrevistas, se possível, com elos ou personagens distintos, mas que fazem parte da unidade de análise. Por outro lado, poderia se realizar uma análise quantitativa antes e após a implantação da tecnologia de processos, especificamente sobre indicadores operacionais e de desempenho da empresa estudada. E por último, sugere-se a replicação desse estudo, mas, em organizações menores que ainda tenham a maior parte de suas operações realizadas manualmente e que estejam passando por um processo de implantação de tecnologias de processos.

\section{Agradecimentos}

Primeiramente à Professora Juliana Bonomi Santos, minha principal referência e incentivadora nessa carreira acadêmica. Depois, aos profissionais da General Motors, Carlos Augusto de Sousa - Assessor de Imprensa, Alcione Viana - Diretora de Relações Públicas, Natália Villar - Estagiária de Relações Públicas e Anderson Faria - Engenheiro de Produção e responsável direto pelas linhas de montagem dos modelos S10 Cabine Simples, Cabine Dupla e a Trailblazer, que na época, auxiliaram na realização desse estudo. 


\title{
Process technology as operations strategy: analysis and operational advantages
}

\begin{abstract}
In the last decades, an alternative used to help operations management and strategy is the implantation of process technology, that means, machines, devices and equipment that can help in the production of services and goods. However, there are some organizations and sectors that still don't use this strategy, perhaps because of the complex analysis needed or high financial investment. Therefore, this article claims to understand how the analysis process works regarding the process technology implementation and what the main benefits from it are, especially when analyzed as operations strategy. Having that in mind, a case study was conducted in a automobile manufacturer where the results and conclusions demonstrate that the implantation of process technology demands of complex analysis with specific dimensions and criteria, but on the other hand, generates robust benefits, especially related to the production capacity and product quality.
\end{abstract}

KEYWORDS: Process Technology. Operations Strategy. Case Study. Quality. Production Capacity. 
REFERÊNCIAS

AMATUCCI, Marcos; BERNARDES, Roberto Carlos. O NOVO PAPEL DAS SUBSIDIÁRIAS DE PAÍSES EMERGENTES NA INOVAÇÃO EM EMPRESAS MULTINACIONAIS-O CASO DA GENERAL MOTORS DO BRASIL. RAI-Revista de Administração e Inovação, v. 4, n. 3, 2007.

ARKADER, Rebecca. A pesquisa científica em gerência de operações no Brasil. Revista de Administração de Empresas, v. 43, n. 1, p. 1-11, 2003.

BARNEY, Jay. Firm resources and sustained competitive advantage. Journal of management, v. 17, n. 1, p. 99-120, 1991. crossref

CHASE, Richard B.; AQUILANO, Nicholas J.; JACOBS, F. Robert. Administração da Produção Para a Vantagem Competitiva. Porto Alegre: Bookman, 2006.

CONSONI, Flavia; BERNARDES, Roberto Carlos; SCUR, Gabriela. Fatores determinantes na atribuição de mandatos globais de P\&D: o caso da General Motors do Brasil. Revista de Administração da Universidade Federal de Santa Maria, v. 10, n. 1, 2017.

CRESWELL, John W. Projeto de pesquisa métodos qualitativo, quantitativo e misto. Porto Alegre: Artmed, 2010.

DAMIÃO, Devanildo; SEVERINO, Patrícia Desenvolvendo a gestão do conhecimento sob o prisma do mapeamento dos processos: Proposta de uma metodologia. Biblioteca Terra Forum Consultores. p. 1-10. Disponível em: $<$ www.terraforum.com.br $>$. Acesso em: 22 jun. 2013.

DE MASI, Domenico. 0 ócio criativo; entrevista a Maria Serena Palieri; tradução de Léa Manzi. Rio de Janeiro: Sextante, 2000.

GAITHER, Normam; FRAZIER, Greg. Administração da produção e operações; tradução José Carlos Barbosa dos Santos; revisão Petrônio Garcia Martins. São Paulo: Pioneira Thomson Learning, 2005.

GENERAL MOTORS DO BRASIL LTDA. Relatório Anual de Sustentabilidade 2011. São Paulo, 2012.

GONÇALVES, José Ernesto Lima. As empresas são grandes coleções de processos. Revista de Administração de Empresas, São Paulo, v. 40, n.1, p. 6-19, Jan./Mar. 2000. crossref

GUARDABASSIO, Eliana Vileide et al. Green factory as a factor of sustainability: the case of GM engine plant in Joinvile-SC. Revista Brasileira de Estratégia, v. 7, n. 3, p. 350, 2014.

Hayes, Robert et al. Produção, estratégia e tecnologia: em busca da vantagem competitiva; tradução Marcelo Klippel. Porto Alegre: Bookman, 2008.

HILL, Terry. Operations Management: Strategic Context and Management Analysis. Ed. MacMillan Business, Londres, 2000. 
JOHNSTON, Robert; CLARK, Graham. Administração de operações de serviço; tradução Ailton Bomfim Brandão; revisão técnica Henrique Luiz Corrêa. - 1. Ed. 7. Reimpr. - São Paulo: Atlas, 2012.

LUZ, Daniel Fonseca da. Transpondo custos para times de chão de fábrica: um estudo de caso na General Motors. Revista Brasileira de Estratégia, v. 2, n. 3, p. $247,2009$.

MACHLINE, Claude. Evolução da administração da produção no Brasil. Revista de Administração de Empresas, São Paulo, v. 34, n.3, p. 91-101, Mai./Jun. 1994.

Maier, F. H; Schroeder, R. G. Competitive product and process technology. IN: Schroeder, R. G.; Flynn, B. B. (Eds.). High performance manufacturing: global perspectives. New York: John Wiley \& Sons, 2001.

MARTINS, Petrônio Garcia; LAUGENI, Fernando Piero. Administração da produção. São Paulo: Saraiva, 1998.

MAXIMIANO, Antonio César Amaru. Introdução à Administração. - Ed. Compacta. - 1. ed. - 5. Reimpr. - São Paulo: Atlas, 2010.

McCUTCHEON, David M.; MEREDITH, Jack R. Conducting case study research in operations management. Journal of Operations Management, v. 11, n. 3, p. 239256, 1993. crossref

MEREDITH, Jack R; SHAFER, Scott M. Administração da produção para MBAs. Porto Alegre: Bookman, 2002.

PAIVA, Ely Laureano; FINGER, Andrew Beheregarai; TEIXEIRA, Rafael. Novas tecnologias e desempenho operacional: um estudo internacional comparativo. Revista de Administração de Empresas, v. 54, n. 2, p. 126, 2014. crossref

PANORAMA. Fábrica Superlativa. Publicação da General Motors do Brasil, São Paulo, Ano 52, n.3, Mar. 2013.

PÉREZ, Omar Lengerke. Uma arquitetura mecatrônica de navegação para veículos com reboques guiados automaticamente em ambientes de sistemas flexíveis de manufatura. 2010.203 f. Tese (Doutorado em engenharia mecânica) - COPPE/UFRJ, Rio de Janeiro, 2010.

PRAHALAD, C. K. A riqueza na base da pirâmide: como erradicar a pobreza com o lucro; tradução de André de Godoy Vieira. - ed. Ver. Atual. - Porto Alegre:

Bookman, 2010.

ROESCH, Sylvia Maria Azevedo. Projetos de estágio e de pesquisa em administração: guia para estágios, trabalhos de conclusão, dissertações e estudos de caso. São Paulo: Atlas, 1999.

ROTH, Aleda V. Applications of empirical science in manufacturing and service operations. Manufacturing \& Service Operations Management, v. 9, n. 4, p. 353$367,2007$. crossref 
SCHROEDER, Roger G. Operations management: Contemporary concepts and cases. Burr Ridge, Illinois: Irwin/McGraw-Hill, 2008

SLACK, Nigel; BRANDON-JONES, Alistair; JohNSton, Robert. Administração da produção. 4. ed. - São Paulo: Atlas, 2015.

et al. Administração da produção. Edição Compacta; revisão técnica Henrique Luiz Corrêa, Irineu Gianesi. - 1. ed. - 15. reimpr. - São Paulo : Atlas, 2012.

. Vantagem competitiva em manufatura: atingindo competitividade em operações industriais; tradução Sônia Maria Corrêa; revisão técnica Luiz Corrêa. 2. ed. - São Paulo : Atlas, 2002.

; LEWIS, Michael. Estratégia de operações; tradução Sandra de Oliveira. 2. ed. - Porto Alegre : Bookman, 2009.

STAKE, R. E. Case Study. IN: N. Denzin \& Y. Lincoln (Org), Handbook of Qualitative Research (p. 235-247). Londres, 1994.

TEECE, David J.; PISANO, Gary; SHUEN, Amy. Dynamic capabilities and strategic management. Strategic management journal, p. 509-533, 1997.

TIGRE, Paulo Bastos. Gestão da inovação: a economia da tecnologia do Brasil. Rio de Janeiro: Elsevier, 2006. - 7ạ reimpressão.

VOSS, Chris; TSIKRIKTSIS, Nikos; FROHLICH, Mark. Case research in operations management. International journal of operations \& production management, v. 22, n. 2, p. 195-219, 2002. crossref

YIN, Robert K. Estudo de Caso: planejamento e métodos. 4. ed. Porto Alegre: Bookman, 2010.

Recebido: 27 abr. 2017

Aprovado: $18 \mathrm{dez} .2017$

DOI: 10.3895/gi.v13n4.5838

Como citar:

LEÃO, W. Tecnologia de processos como estratégia de operações: avaliação e vantagens operacionais. $\mathbf{R}$.

Gest. Industr., Ponta Grossa, v. 13, n. 4, p. 154-170, out./dez. 2017. Disponível em

<https://periodicos.utfpr.edu.br/rgi>. Acesso em: XXX.

Correspondência:

Wandick Leão

Rua Quatá, n. ${ }^{\circ} 300$, VI. Olímpia, São Paulo, Brasil.

Direito autoral: Este artigo está licenciado sob os termos da Licença Creative Commons-Atribuição 4.0

Internacional.

\section{(c) (i)}

